\title{
Unusual Rectal Foreign Body: Treatment Using Argon-Beam Coagulation
}

A 44-year-old homosexual man had introduced a large, cellophane-covered green apple into the rectum 24 hours before admission, probably with the aim of sexual stimulation. Spontaneous defecation was subsequently not possible. The sigmoidoscopy showed the intact covered apple within the rectum (Figure 1). Since it was not possible to remove the apple with the ordinary endoscopic instruments, the surface of the solid foreign body was treated with the argon-beam coagulator (Arco-MC, Söring, Quickborn, Germany; level 3, gas flow $4 \mathrm{l} / \mathrm{min}$, power $110 \mathrm{~W}$ ), melting down the apple continuously. The cellophane cover was soon removed using a foreign-body removal forceps. With progressive size reduction, several attempts to catch the remainder with a slins failed. After two and a half hours of intermittent coagulation, the size of the apple had been reduced by more than $50 \%$. Severa parts were additionally removed with the foreign-body forceps and a remnant with a relatively soft consistency was finally lef (Figure 2), which was easily passed with defecation the followins morning. 


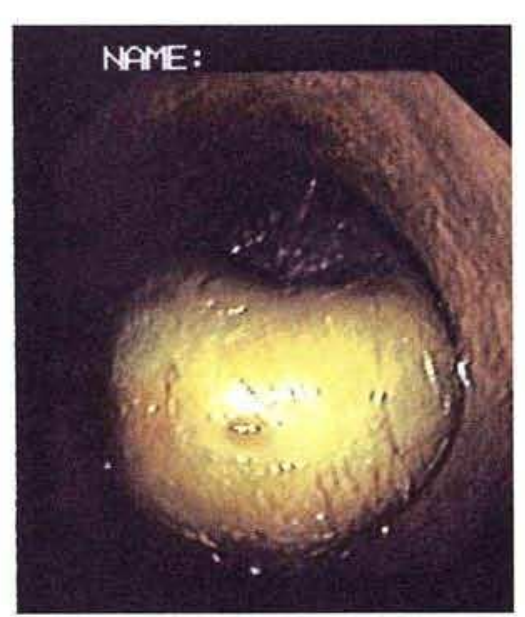

Figure 1: Endoscopic view of the cellophane-covered green apple within the rectum.

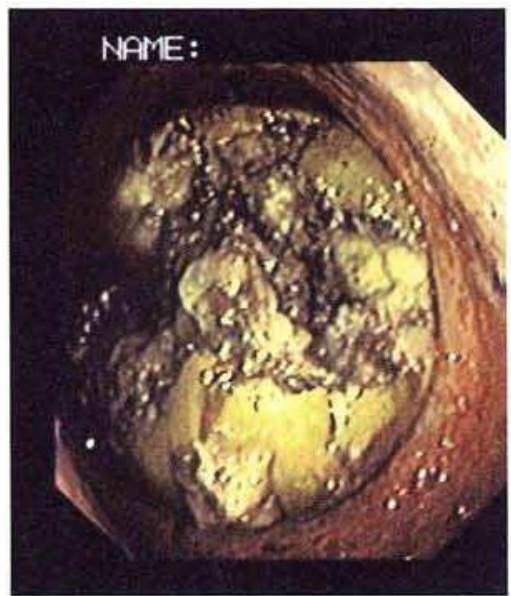

Figure 2: Soft remnant of the apple after argon-beam coagulation.
In argon-beam coagulation, high-frequency alternating current is applied without contact with the target object $(1,2)$. The case described shows that the argon beamer can even be used to zoagulate large organic foreign bodies.

\section{J. Glaser, T. Hack, M. Rübsam}

Dept. of Internal Medicine and Gastroenterology, District Hospital, Fulda, Germany

\section{References}

1. Johanns W, Jakobeit C, Luis W, et al. Kontaktlose Argon-GasKoagulation in der flexiblen Endoskopie des Gastrointestinaltrakts: In-vitro-Untersuchungen und erste klinische Erfahrungen. Z Gastroenterol 1995; 33: 694-700.

2. Farin G, Grund KE. Technology of argon plasma coagulation, with particular regard to endoscopic applications. Endosc Surg $1994 ; 2: 71-7$

\section{Corresponding Author}

J. Glaser, M.D.

Abteilung für Allgemeine Innere Medizin und Gastroenterologie

Herz-Jesu-Krankenhaus

Buttlarstrasse 74

36039 Fulda

Germany

Fax: +49-661-15309 